\title{
Góc nhìn hoàn toàn mó́i cho giới khoa học về vấn đề tự tử
}

EFR - Trung bình trên thế giới cứ mỗi 40 giây lại có 1 người tự tử, đồng nghĩa với việc cứ mỗi năm lại có 800 nghìn người chểt. Nhóm tác giả tại Trường đại học Phenikaa đã lý giải quá trình hình thành ý nghĩ tự tử theo một cách hoàn toàn mới, trong bài viết đăng trên Tạp chí International Journal of Environmental Research and Public Health mới đây.

Ở Nhật Bản, số người tự tử trong tháng 10 năm 2020 còn nhiều hơn cả số người thiệt mạng do Covid từ đầu năm cộng lại. Điều này đặt ra một câu hỏi: Họ đang phải đối mặt với những điều gì mà lại chọn phương án cực đoan đến thế?

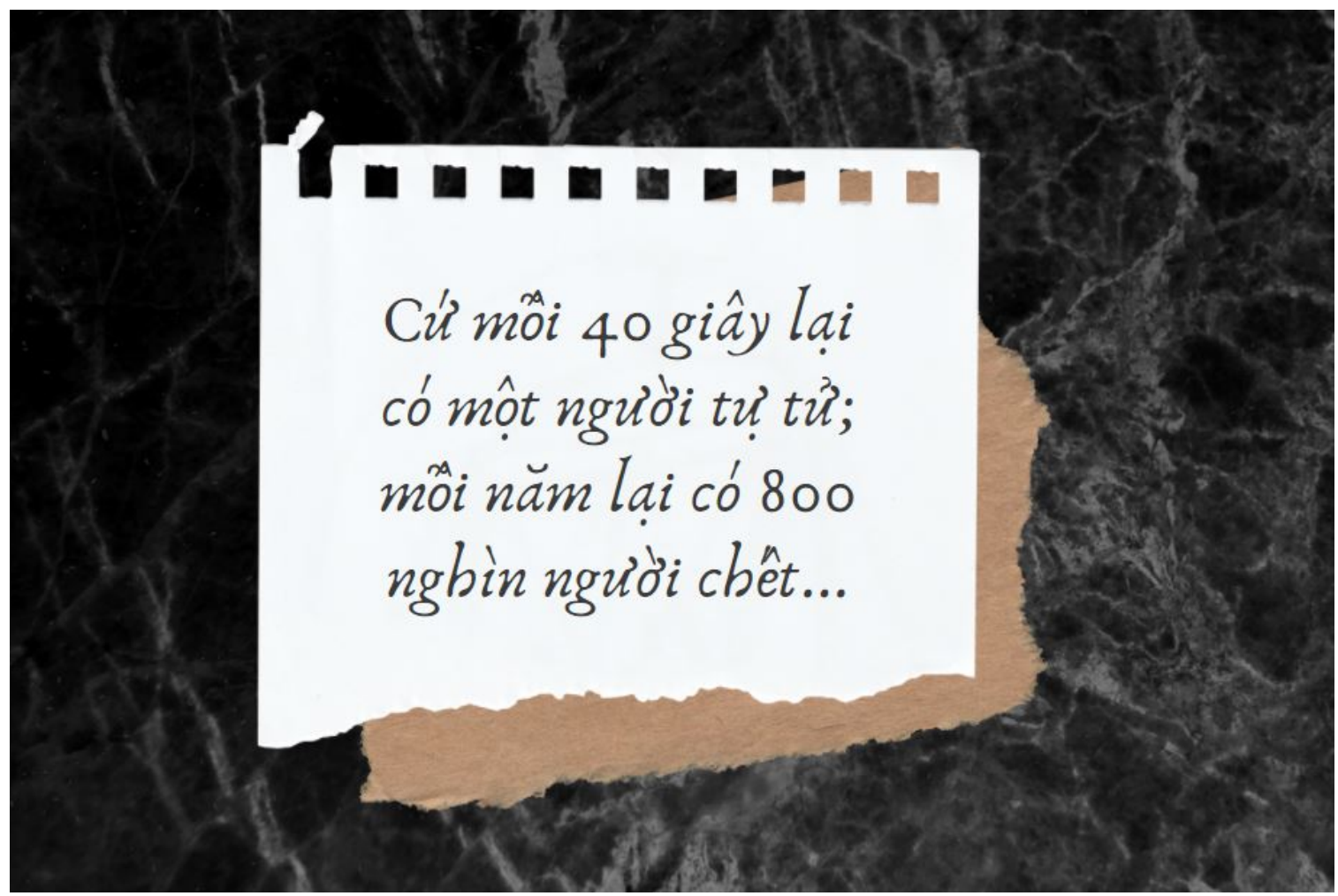

Nhóm tác giả chỉ ra 3 điều kiện để ngăn chặn việc hình thành suy nghĩ tự tử

Trước đây, có nhiều nhà nghiên cứu từ nhiều trường phái tư tưởng khác nhau đã đề xuất lý thuyết giải thích cho nguyên nhân dẫn đến ý định tự tử, thế nhưng nghiên cứu thực nghiệm lại cho ra nhiều kết quả mâu thuẫn, không đúng với lý thuyết. Điều này có nghĩa, vẫn còn nhiều khoảng trống trong lý thuyết giải thích sự phức tạp của quá trình hình thành ý nghĩ tự tử.

Mới đây, một nhóm tác giả từ Trung tâm Nghiên cứu Xã hội Liên ngành (ISR), Trường Đại học Phenikaa đã đề nghị lý giải quá trình hình thành ý nghĩ tự tử dựa trên cơ chế xử lý thông tin (cụ thể là cơ chế Mindsponge) [1,2]. Bài nghiên cứu có tựa đề "Alice in Suicideland: Exploring the Suicidal Ideation Mechanism through the Sense of Connectedness and HelpSeeking Behaviors" đã được xuất bản trên Tạp chí International Journal of Environmental Research and Public Health [Citescore $2019=3.0$, JIF $2019=2.849$, Q1]. Được biết, trước đây một số thành viên trong nhóm nghiên cứu cũng đã có nhiều bài nghiên cứu đáng chú ý 
về vấn đề sức khỏe tâm lý học đường [3,4,5]

Cách lý giải sử dụng cơ chế xử lý thông tin Mindsponge của nhóm tác giả đã đưa ra một góc nhìn hoàn toàn mới cho giới khoa học về vấn đề tự tử. Góc nhìn này được kỳ vọng sẽ giải thích các mâu thuẫn giữa các lý thuyết trước đây về việc hình thành ý nghĩ tự tử và giúp các nhà nghiên cứu và chuyên gia tư vấn sức khỏe tâm lý có cái nhìn sâu hơn về vấn đề tự tử.

Cụ thể, nghiên cứu Alice in Suicideland đã sử dụng cơ chế nạp, xả, và xử lý thông tin Mindsponge và bộ dữ liệu về sức khỏe tinh thần của 268 sinh viên đa quốc gia $(75 \%$ sinh viên quốc tế và $25 \%$ sinh viên Nhật Bản) để giải thích cơ chế dẫn đến suy nghĩ tự tử thông qua cảm giác kết nối và hành vi tìm kiếm trợ giúp về mặt tinh thần [6].

\section{Cơ chế Mindsponge về quá trình hình thành ý định tự tử và tìm kiếm giúp đỡ}

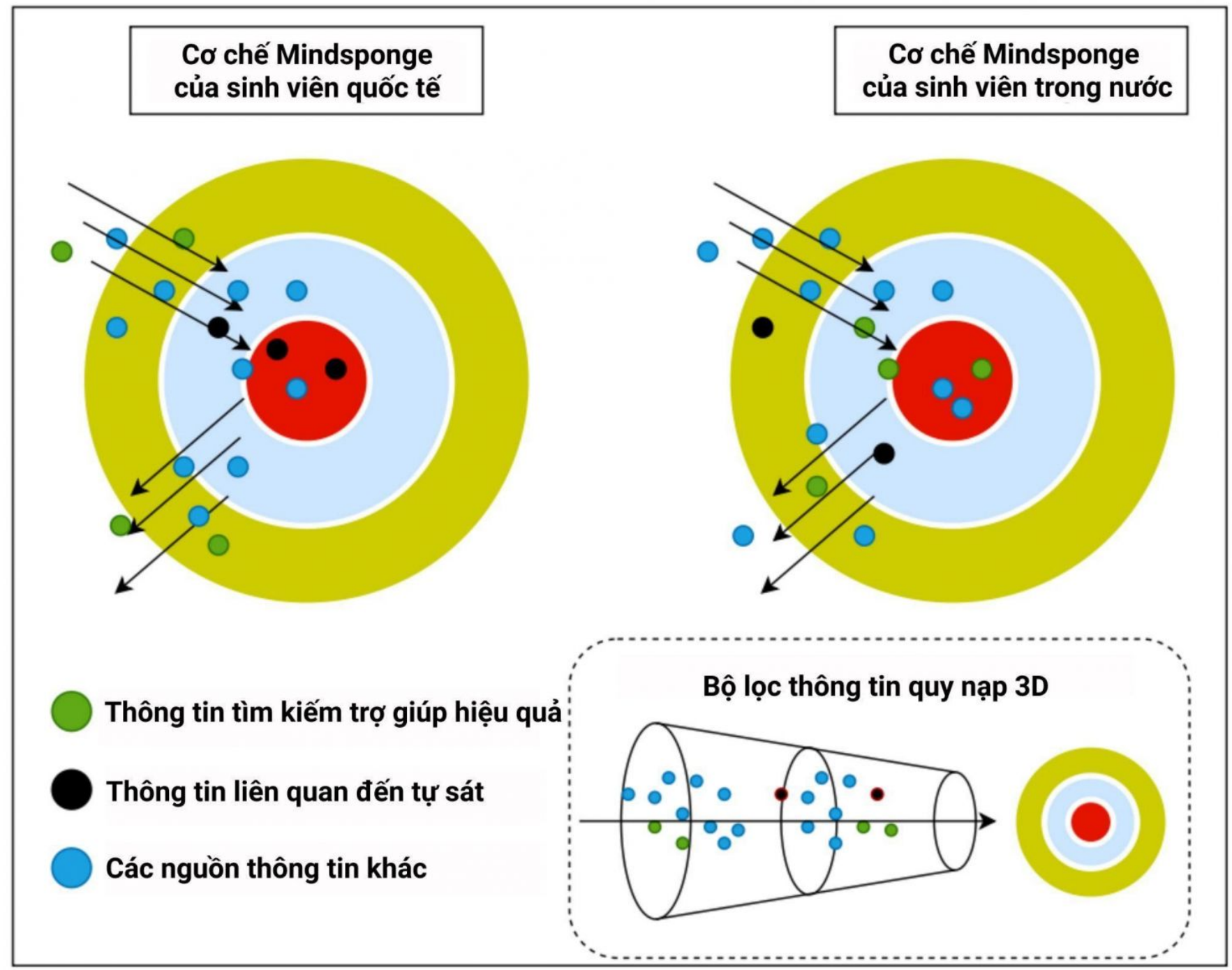

Nguồn: Nguyen et al. (2021)

Hình trên thể hiện quá trình nạp xả thông tin liên quan đến ý tưởng tự tử và nguồn thông tin trợ giúp hữu ích ở hai nhóm người: sinh viên quốc tế và sinh viên Nhật Bản. Hình tròn màu đỏ là tập hợp các niềm tin của sinh viên, nơi lưu trữ những giá trị cốt lôi và quan trọng ảnh hưởng đến hành vi và suy nghĩ. Trong khi đó vòng tròn màu xanh lam nhạt là vùng đệm trong quá trình thu nạp thông tin. Để thông tin đi từ môi trường xung quanh (màu vàng) vào trong khu vực chứa đựng giá trị cốt lõi của sinh viên, nó phải vượt qua được bộ lọc thông tin $3 \mathrm{D}$. Bộ lọc thông tin 3D là quá trình hấp thu các thông tin có ích và loại bỏ các thông tin 
không có ích bằng cách phán đoán chi phí-lợi ích mà thông tin đem lại dựa trên các giá trị cốt lõi sẵn có của học sinh và môi trường xung quanh.

Nhìn vào đây, đầu tiên ta thấy thông tin từ môi trường xung quanh (vòng tròn màu vàng) gồm thông tin trợ giúp hiệu quả (từ người thân hoặc từ bác sĩ), thông tin liên quan đến việc tự tử và các nguồn thông tin khác. Theo tác giả, sự xuất hiện suy nghĩ tự tử là biểu hiện của việc người trong hoàn cảnh bế tắc không tìm kiếm được nguồn trợ giúp hữu hiệu khi gặp phải các khó khăn và đau đớn về mặt tinh thần (áp lực tâm lý về thành tích học tập, trầm cảm, cô đơn, lo lắng, v.v.). Khi không đạt được nguồn thông tin trợ giúp cần thiết, nhân sự sẽ có xu hướng tìm kiếm những giải pháp thay thế, trong đó có việc tự tử. Vậy tại sao tự tử được xem như một lựa chọn? Đó là vì đối với những người đang gặp khó khắn, đau đớn, và dằn vặt về mặt tinh thần, cái chết có thể xem như là giải pháp giúp giải thoát bản thân họ khỏi nỗi thống khổ tinh thần khi các lựa chọn khác đều lâm vào bế tắc.

Vậy làm sao để ngăn chặn việc hình thành suy nghĩ tự tử hữu hiệu? Để làm việc đó, nhóm tác giả gợi ý rằng, ba điều kiện sau phải đồng thời được thỏa mãn: 1) xây dựng sự tin tưởng và gắn kết với người đang gặp khó khăn về tinh thần; 2) Cung cấp các nguồn thông tin trợ giúp về mặt tinh thần hiệu quả; 3) Giảm định kiến của xã hội đối với những người gặp khó khăn về mặt tinh thần, qua đó khiến họ dễ dàng hơn trong việc chia sẻ và tìm kiếm giúp đỡ.

Qua đây, có thể thấy rằng việc ngăn chặn các hành vi cực đoan, như tự tử, là có thể thực hiện được khi người thân, gia đình, và xã hội có sự thấu hiểu, cảm thông hơn đối với những người đang gặp khó khăn về cảm xúc và tinh thần. Khi có thể, đừng biến họ thành những người cô độc và mất đi ý nghĩa sống.

\section{Tài liệu tham khảo}

1. Vuong, Q. H., \& Napier, N. K. (2015). Acculturation and global mindsponge: An emerging market perspective. International Journal of Intercultural Relations, 49, 354-367. https://doi.org/10.1016/j.ijintrel.2015.06.003

2. Vuong, Q.H (2016) Global mindset as the integration of emerging socio-cultural values through mindsponge processes: A transition economy perspective. In J. Kuada (Ed.), Global Mindsets: Exploration and Perspectives (pp. 109-126). London: Routledge.

3. Nguyen, M.H. et al. (2019). Internationalization and Its Discontents: Help-Seeking Behaviors of Students in a Multicultural Environment Regarding Acculturative Stress and Depression. Sustainability, 11(7), 1865. https://doi.org/10.3390/su11071865

4. Nguyen, M.H. et al. (2019). Depression, Acculturative Stress, and Social Connectedness among International University Students in Japan: A Statistical Investigation. Sustainability, 11(3), 878. https://doi.org/10.3390/su11030878

5. Nguyen, M.H. et al. (2020). A Scientometric Study on Depression among University Students in East Asia: Research and System Insufficiencies?. Sustainability, 12(4), 1498. https://doi.org/10.3390/su12041498

6. Nguyen, M.H. et al. (2021). Alice in Suicideland: Exploring the Suicidal Ideation Mechanism through the Sense of Connectedness and Help-Seeking Behaviors. International Journal of Environmental Research and Public Health, 18(7), 3681. https://doi.org/10.3390 /ijerph18073681 